\title{
华南早、中奥陶世尖顶笔石属(Acrograptus)的始端 发育、系统分类及扩散型式
}

\author{
李丽霞*，冯洪真，王文卉，陈文建 \\ 南京大学地球科学与工程学院, 南京 210093 \\ *E-mail: lilixia1015@gmail.com \\ 收稿日期: 2011-12-07; 接受日期: 2012-05-01 \\ 国家自然科学基金项目(批准号: 40972009)资助
}

\begin{abstract}
摘要 通过对采自湖南益阳南坝剖面的 Acrograptus 标本的研究, 本文对该属作了如下厘定: 笔石体两枝近水平至下斜伸展, 胎管长且纤细; th $1^{1}$ 从亚胎管始部生出, th $1^{2}$ 为双芽胞管, 始端发 育型式为等称笔石型(isograptid); th $1^{1}$ 和 th $1^{2}$ 在不同水平位置弯离胎管, 导致始端部分不对称; th $1^{2}$ 与 th $2^{1}$ 的原胞管部分极为纤细, 构成两个细弱的横管. 经厘定后, Acrograptus 归入均分笔石 科、弯笔石亚科, 共包含 6 个种: A. affinis (Nicholson), A. filiformis (Tullberg), A. gracilis (Törnquist), A. nicholsoni (Lapworth), A. pusillus (Tullberg)以及 A. saukros (Ni). 这 6 个种在华南广 泛分布, 其中在上扬子区和江南区中东部较为集中。进一步研究表明, 在华南, 最早的 Acrograptus 于弗洛初期出现在水体较深的斜坡相区. 弗洛期Pendeograptus fruticosus 带初, 该属 经历了一次明显的扩散事件, 属内各种由斜坡向较浅水的台地迁移. 这一扩散事件可能直接受 控于弗洛中期一次大规模的海侵事件.
\end{abstract}

关键词

始端发育

系统分类

扩散型式

尖顶笔石属

奥陶纪

华南
尖顶笔石属(Acrograptus)最早由 Tzaj $^{[1]}$ 建立，用 以区分对笔石属(Didymograptus)中两枝下斜的类群 (即文献[2]所划分的 Group II-Type D. affinis). 以 Didymograptus affinis Nicholson, 1869 为模式种, Tzaj 将该属定义为: 笔石体两枝下斜伸展, 胞管长且纤细, 倾角小, $10 \mathrm{~mm}$ 内有 7 12 个胞管, 包括 A. affinis (Nicholson), A. gracilis (Törnquist), A. nicholsoni (Lapworth) 以及 A. pusillus (Tullberg)等 33 个种. 属内 各种广泛分布于全球弗洛期至达瑞威尔期的地层中 ${ }^{[1]}$.

最初的定义主要强调 Acrograptus 在笔石枝形态 上与 Didymograptus 中其他种类的差别, 大量笔石枝 纤细、下斜的对笔石类均被归入其中 ${ }^{[1]}$. 随着研究的
深入, Acrograptus 的始端发育开始备受关注, 对该属 的认识也随之不断变化.

关于 Acrograptus 的始端发育特征，不同学者持 有不同观点: Bouče $\mathrm{K}^{[3]}$ 认为 Acrograptus 的始端发育型 式不仅有 isograptid 型(A. lipoldi), 可能也有 artus 型 (A. nicholsoni); Bulman ${ }^{[4]}$ 以及 Skevington ${ }^{[5]}$ 在研究中 也发现一些与典型的 Acrograptus 在特征上相似的种 (Didymograptus aff. gracilis), 他们认为这些种的始端发 育型式应为 artus 型; 而 Maletz ${ }^{[6]}$ 通过 Didymograptus 的 始端发育研究则认为, Acrograptus 的始端发育型式 只有 isograptid 型一种. 此外, 有关该属 th $1^{1}$ 的生出位 置也有两种不同认识, 即在亚胎管较低位置生出或

中文引用格式: 李丽霞, 冯洪真, 王文卉, 等. 华南早、中奥陶世尖顶笔石属(Acrograptus)的始端发育、系统分类及扩散型式. 中国科学: 地球科学, 2013, 43: 19-32 英文引用格式: Li L X, Feng H Z, Wang W H, et al. Proximal development, systematic taxonomy, and dispersal pattern of the Early-Middle Ordovician graptolite Acrograptus from South China. Science China: Earth Sciences, 2012, 55: 1110-1122, doi: 10.1007/s11430-012-4436-x 
亚胎管顶端生出 ${ }^{[5,6]}$.

依据始端形态特征, Cooper 和 Fortey ${ }^{[7]}$ 将 Acrograptus 的定义修订为: 笔石体具弯笔石式分枝 型式, 笔石枝水平到下斜伸展, 始部枝宽较小, 约 0.5 $\mathrm{mm}$. 同时, 将该属归入均分笔石科(Dichograptidae)弯 笔石亚科 (Sigmagraptinae). 随后, Williams 和 Stevens ${ }^{[8]}$ 则将该属置于中国笔石科(Sinograptidae)弯 笔石亚科. 李积金等 ${ }^{[9]}$ 认为 Acrograptus 具有与棱笔 石相似的分枝特征，因而将该属置于棱笔石科 (Goniograptidae). 然而, 上述修订均未对 Acrograptus 的始端发育特征进行详细描述及讨论.

目前, Acrograptus 的始端发育特征仍不明确. 究 其原因, 一方面在于初始定义并没有对该属的始端 发育给出较为确切的描述, 而长期以来, 对于始端发 育在分类上的意义也未得到应有的重视; 另一方面, 笔石体的始端发育情况受标本保存状况的直接影响. 在泥岩或页岩中, 笔石体多呈薄膜状保存, 始端部分 各细节较难辨认，始端发育型式不容易确定.

作者最近考察湖南益阳南坝剖面时发现, 该剖 面早、中奥陶世笔石地层发育良好, Acrograptus 产出 层位较多, 且多为矿化立体保存, 始端结构清晰, 是 深入研究该属的理想产地. 此次地质考察, 作者共在 14 个层位采得 128 枚 Acrograptus 标本, 分属 3 个种 类: A. affinis (Nicholson), A. gracilis (Törnquist)和 $A$. nicholsoni (Lapworth). 根据这些标本, 同时结合其他 学者所采集的 Acrograptus 标本, 本文对该属的始端 发育进行了深入探讨, 并以此为基础, 对该属的定义 和分类进行了修订. 此外, 本文也对 Acrograptus 在 华南的扩散型式做了进一步分析.

\section{1 产地与分布}

华南古板块的奥陶系被划分为三个主要的地层 区: 扬子区、江南区和东南区, 在古地理格局上分别 对应扬子台地、江南斜坡、东南盆地 ${ }^{[10,11]}$. 本文所涉 及的 Acrograptus 标本, 主要来自隶属于江南区的湖 南益阳南坝剖面. 同时, 本文也仔细观察了其他学者 在华南各地层区所采集的 Acrograptus 标本. 现将主 要产地介绍如下:

\section{1 湖南益阳}

南坝剖面位于距湖南省益阳市西南约 $30 \mathrm{~km}$ 处
的南坝村, 地处江南斜坡中部(图 1), 以笔石页岩相 沉积为特征 ${ }^{[13]}$. 剖面近南北向展布, 总厚度 $109.12 \mathrm{~m}$ 左右, 地层连续, 出露良好, 由印渚埠组和宁国组组 成, 二者呈整合接触. 印渚埠组上部主要由深灰色、 蓝灰色、灰绿色、灰黑色块状泥岩及土黄色、黄绿色 粉砂质薄层状泥岩夹层构成. 宁国组则以黄绿色、灰 绿色块状泥岩为主, 偶夹数层土黄色粉砂质薄层, 微 层理发育, 风化后呈红褐色、褐色片状. 剖面中弗洛 阶/特马道克阶界线附近地层连续, 界线位于宁国组 内部, 高于印渚埠组/宁国组的界线.

前人已对南坝剖面作了不少研究工作, 重点是晚 特马道克期的笔石古生物学与地层学 ${ }^{[13,14]}$, 而对于弗 洛期笔石动物群的研究仅限于其底部的 Tetragraptus approximatus 带. 基于详细了解该剖面弗洛期生物面 貌及地层资料的目的，笔者曾多次前往南坝剖面采 集标本, 通过细致、审慎的属种鉴定, 在南坝剖面弗 洛阶中共识别出 13 属 28 种, 自下而上确立了 4 个笔 石带, 即 Tetragraptus approximatus 带、Pendeograptus fruticosus 带、Didymograptellus bifidus 带和 Corymbograptus deflexus 带. 这 4 个笔石带组成的弗洛期笔石 带序列可与斯堪的纳维亚、加拿大、美国等地同期地 层中的笔石带序列精确对比 ${ }^{[15,16]}$.

南坝剖面中发现的 Acrograptus 共计 3 种, 即 A. affinis (Nicholson), A. gracilis (Törnquist)和 A. nicholsoni (Lapworth). 标本产于宁国组深色泥岩中, 矿化立体保 存. 该属最早出现于弗洛期 Pendeograptus fruticosus 带, 在 Didymograptellus bifidus 带达到繁盛, 并上延至 Corymbograptus deflexus 带(图 2).

\section{2 江西玉山}

玉山地处江西省东北部，与浙江西部江山、常山 接壤, 在地层区划上隶属于江南区(图 1). 玉山地区 早、中奥陶世含笔石地层发育良好, 相关研究工作主 要集中于玉山古城乡一带, 包括牟家坞、李家蓬(山头 底)、陈家坞等剖面. 目前, 在该地区弗洛期至达瑞威 尔期地层中已确立的笔石带共 13 个 ${ }^{[17,19,20]}$. 玉山地区 产出的 Acrograptus 共计 6 种: A. affinis (Nicholson), A. gracilis (Törnquist), A. nicholsoni (Lapworth), A. filiformis (Tullberg), A. pusillus (Tullberg) 以及 A. saukros (Ni). 其中, A. nicholsoni 和 A. pusillus 为最早 出现的两个种, 首现于 T. approximatus 带, A. gracilis 的末现可达玉山地区的 P. elegans 带顶部(图 2). 


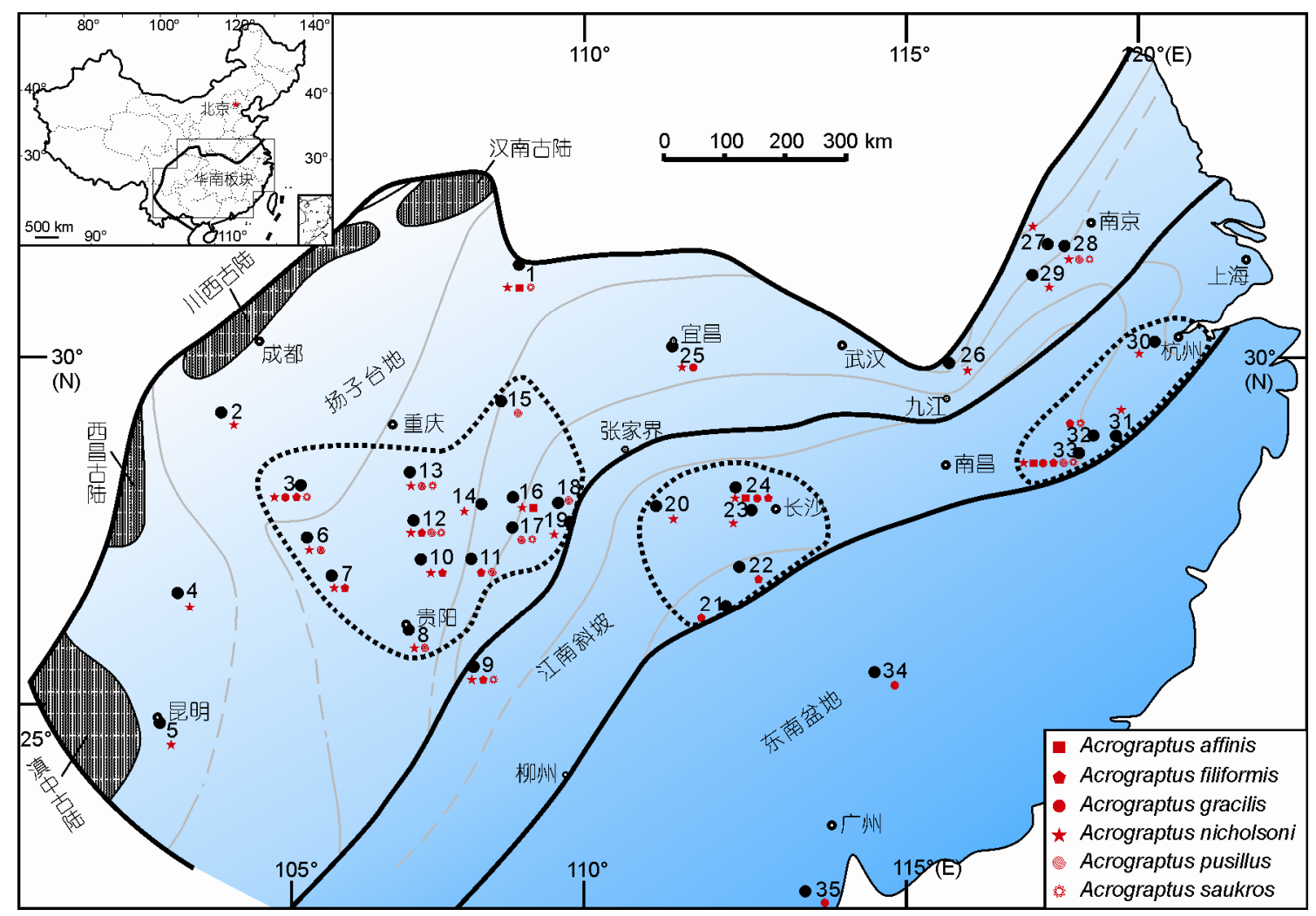

图 1 早、中奥陶世尖顶笔石属(Acrograptus)在华南板块的地理分布

1. 重庆城口杨家坝; 2. 四川峨眉山高洞; 3. 四川长宁双河; 4. 云南巧家牛角厂; 5. 云南昆明红石崖; 6. 云南威信县白果树; 7. 贵州毕节燕子 口; 8. 贵州贵阳乌当; 9. 贵州三都大塘, 下燕高; 10. 贵州遵义马蹄沟; 11. 贵州湄潭五里坡; 12. 贵州桐梓红花园; 13. 重庆綦江观音桥; 14. 贵州务川; 15. 重庆石柱双流坝; 16. 贵州沿河甘溪; 17. 贵州思南英武溪; 18. 重庆秀山; 19. 贵州松桃; 20. 湖南安化; 21. 湖南祁东; 22. 湖南 双峰桥亭子; 23. 湖南宁乡; 24. 湖南益阳南坝; 25. 湖北宜昌黄花场; 26. 安徽宿松龙山; 27. 安徽含山; 28. 安徽和县三道坝; 29. 安徽无为横 山; 30. 浙江于潜乐平; 31. 浙江龙游石佛; 32. 浙江常山黄泥塘; 33. 江西玉山陈家坞、牟家坞、李家蓬、白坞; 34 . 江西崇义过埠樟木曲; 35 . 广

东台山. 由于华夏古陆的含义及使用尚存争议, 图中暂不标识; 古地理图部分改自文献[12]

\section{3 贵州桐梓}

红花园剖面位于黔北桐梓县城东南约 $7 \mathrm{~km}$ 的红 花园村, 在地层区划上隶属于扬子区(图 1). 剖面地 层连续, 早、中奥陶世湄潭组富含大量笔石化石，自 下而上可划分为 8 个笔石带: Acrograptus filiformis 带、Didymograptellus eobifidus 带、Corymbograptus deflexus 带、Azygograptus suecicus 带、Expansograptus hirundo 带、Exigraptus clavus 带、Undulograptus austrodentatus 带以及 Undulograptus intersitus 带. Acrograptus 在红花园剖面中产出 4 个种：A. nicholsoni (Lapworth), A. filiformis (Tullberg), A. pusillus (Tullberg) 以及 A. saukros $(\mathrm{Ni})$. 这 4 个种在剖
面中的延限相对较短, 仅从 A. filiformis 带上延至 Didymograptellus eobifidus 带底部 ${ }^{[22 ~ 24], 1)}$ (图 2).

\section{2 始端发育}

\section{1 均分笔石类(dichograptoids)的始端发育}

长期以来，笔石枝的形态特征被作为均分笔石 分类的主要依据. 随着研究深入, 这种纯粹的“形态” 分类不断遭到质疑. 目前，这种以笔石枝形态为基础 的分类系统逐步被学者们所摒弃, 转而将目光聚焦 于笔石体始端发育特征上, 并将其作为重新划分均 分笔石类的重要依据.

1) 王汝植. 奥陶系. 见: 地矿部成都地质矿产研究所, 编. 西南地区地层总结, 1981.115 


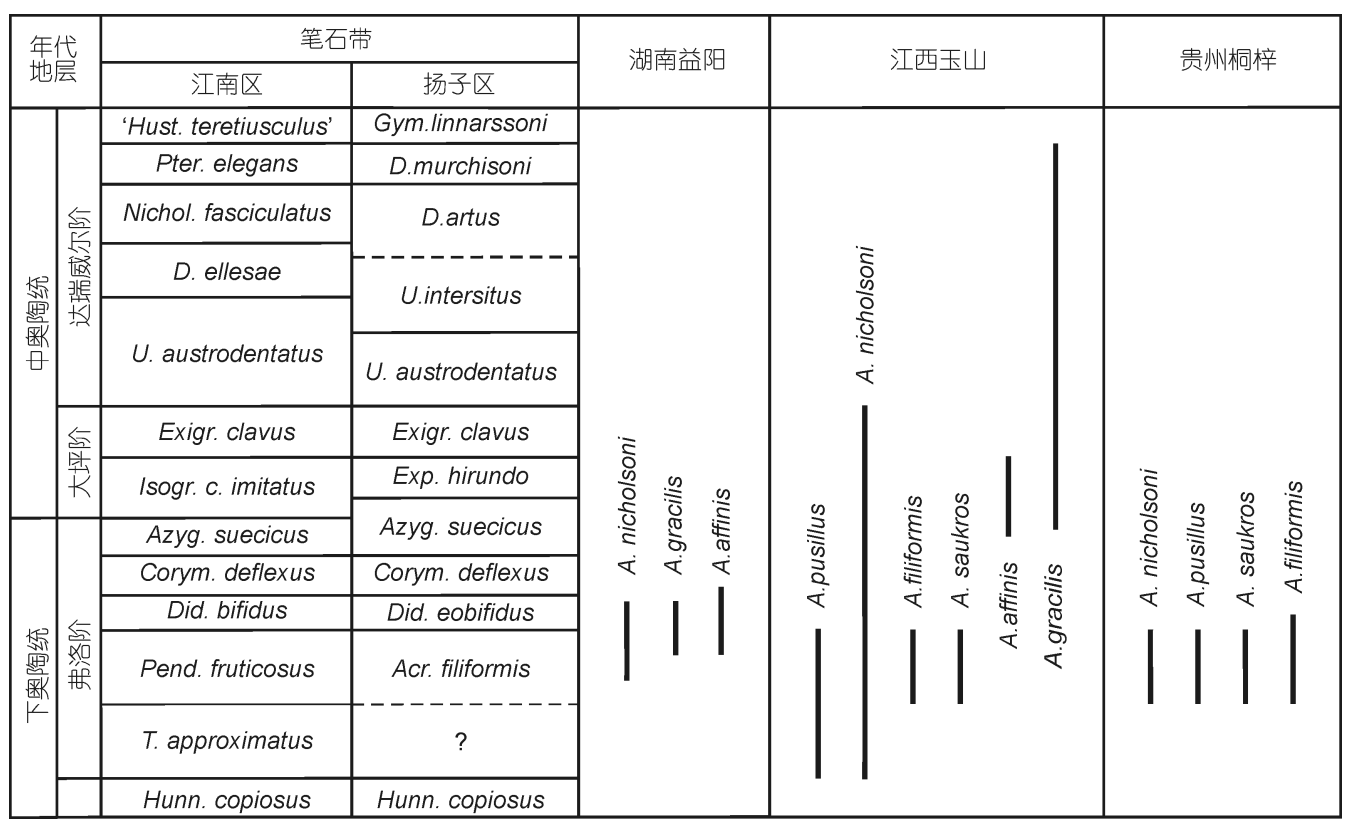

图 2 华南主要产地早、中奥陶世尖顶笔石属(Acrograptus)的地层延限

江西玉山资料来源于文献[17 21]; 贵州桐梓资料来源于文献[22 24],1). 笔石带序列修改自文献[25]

最初, 对于笔石体始端的研究只是将其发育型式 进行简单划分, 各个发育型式间被认为是连续变化 的 ${ }^{[26-30]}$. 均分笔石类的始端发育型式有多种，各种发育 型式又被分为不同的阶期，同一发育型式内的不同阶 期存在某种联系, 代表一个连续变化的演化序列 ${ }^{[4,31 ~ 33]}$. 此时, 学者们关注的仅是笔石体始端发育诸多特征中 的几个特征, 如双芽胞管所处的位置和生长方向, 以及 从双芽胞管上生出的两个胞管的特征，对于始端发育 的其他特征涉及甚少，从而忽略了始端构造特征的多 变性及其在确定系统发育和分类方面的重要性.

Cooper 和 Fortey ${ }^{[34]}$ 修订了 Bulman ${ }^{[4,31,33]}$ 最初关于 均分笔石类始端发育型式的复杂模型, 将均分笔石类 的始端发育型式划分为两类: artus 型和 isograptid 型, 其中 isograptid 型较为原始, artus 型是从 isograptid 型 演化而来. 同时, 他们把始端发育型式与始端构造作 为两个独立的概念区分开来, 认为始端发育型式是 高度保守的性状特征, 而始端构造则具有较大的可 变性, 后者在解释系统发育关系的相关问题上显得 更为重要 ${ }^{[35]}$. 尽管 Cooper 和 Fortey ${ }^{[34]}$ 所确立的始端发 育型式很大程度上简化了最初的繁琐模型, 然而仅凭 其解释均分笔石类复杂多变的始端发育还是颇为困难 的. 随着分支系统学在系统发育研究中的应用与发展, 笔石体始端发育的重要性更加突出. 一些彼此独立的
特征将从有关始端发育的众多特征中选出, 作为重要 的性状用于编码。这其中不仅包括了 Cooper 和

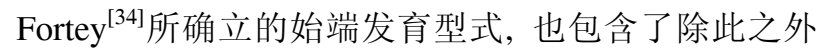
的其他始端发育特征(如他们所定义的始端构造) ${ }^{[35 \sim 37]}$.

最近, Toro 和 Maletz ${ }^{[38]}$ 在笔石体始端发育的众 多特征中遴选出 4 个相互独立的特征: (1) th $1^{1}$ 的生出 位置(原胎管或亚胎管)(图 3(a) (c))；(2) 双芽胞管所 处的位置(th $1^{1}$ 或 th $1^{2}$ ); (3) 双芽胞管的生出位置(左 或右); (4) 双芽胞管的生长方向 (左旋或右旋)(图 3(d) (f)). 这些特征的选取为均分笔石类的分类学研 究提供了简便、高效的指导工具. 然而, 本文认为上 述 4 个特征的重要性不同, 双芽胞管所处的位置在均 分笔石分类中起着决定性作用, 其次是 th $1^{1}$ 的生出位 置, 其余特征次之. 依双芽胞管所处的位置, 均分笔 石类的始端发育分为两种类型: 若 th $1^{1}$ 为双芽胞管, 始端发育型式为 artus 型; 若 th $1^{2}$ 为双芽胞管，始端 发育型式则为 isograptid 型. 其中 isograptid型占多数, 只有少数是 artus 型. Th $1^{1}$ 的生出位置可以在胎管较 高位置的原胎管处，也可以在胎管中部的亚胎管处. 双芽胞管的生出位置与其生长方向具有一定的关联, 一般左侧生出的双芽胞管对应左旋模式，而右侧生 出的双芽胞管对应右旋模式 ${ }^{[6,8,38]}$.

本文的均分笔石类(dichograptoids)是非正式用法, 


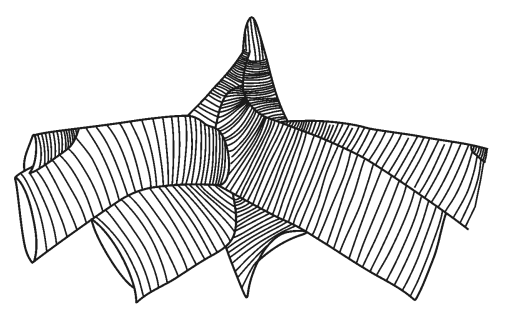

(a)

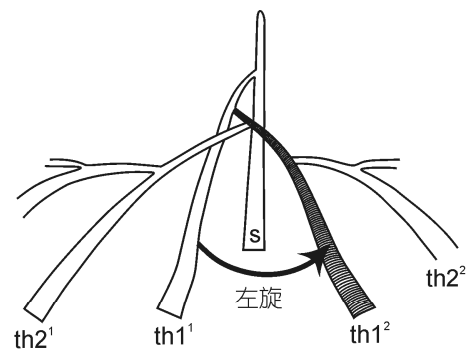

(d)

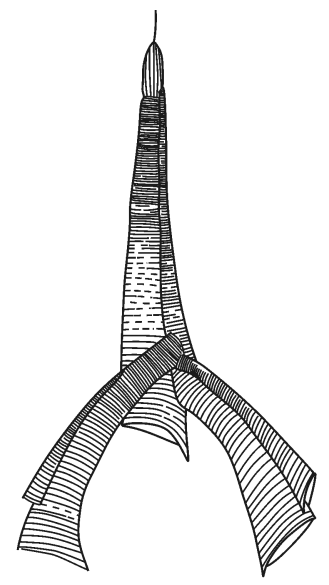

(b)

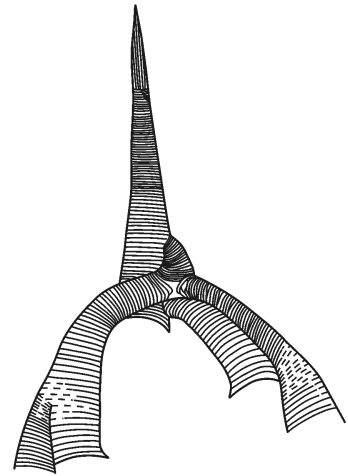

(c)

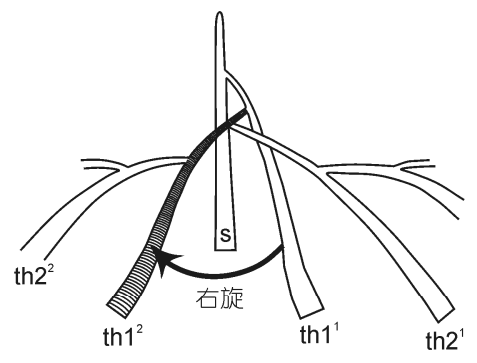

(e)

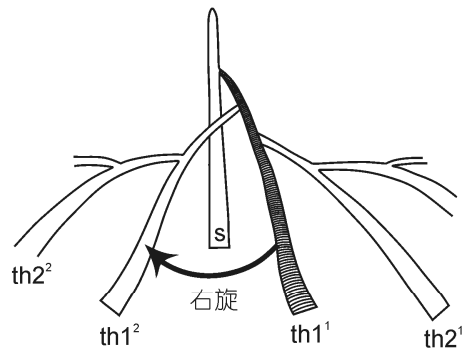

(f)

图 3 均分笔石类始端发育型式

修改自文献[8,33,38]. (a) (c) 始端发育复原图; (d) (f) 始端发育型式图解. (a) Expansograptus holmi; (b) Pendeograptus fruticosus; (c) Baltograptus minutus; (d) isograptid 型, 左旋; (e) isograptid 型, 右旋; (f) artus 型, 右旋. (d) (f)中双芽胞管均用黑色条带标识, 箭头指示双芽胞 管的生出位置

泛指具有均分笔石式发育型式的种类 ${ }^{[34]}$, 包括均分笔 石科(Dichograptidae)和叶笔石科(Phyllograptidae), 相 当于 Bulman ${ }^{[33]}$ 的均分笔石科.

\subsection{Acrograptus 的始端发育}

关于 Acrograptus 的始端发育型式问题一直颇具 争议. Bulman ${ }^{[4]}$ 曾指出, 产自瑞典 Llanvirn 期的一些 标本具有 artus 型始端发育型式, 它们与典型的 Arenig 期标本 (现认为是 Acrograptus) 在很多方面较 为相似. 瑞典 Llanvirn 期的标本虽为立体保存, 但是 始端结构无法清晰辨认. 其中被认为是 A. gracilis 的 标本在图像上看不到 artus 型的特征, 反而在胎管处 发现有类似横管的结构, 与 isograptid 型较为相似. 此后, Skevington ${ }^{[5]}$ 也发现一些与 A. gracilis 相似的种 类(Didymograptus aff. gracilis), 其始端发育型式虽为 artus 型, 但 th $1^{1}$ 的生出位置并非在胎管近顶端处, 而 是较典型的Acrograptus 低. 1973 年, Bouček ${ }^{[3]}$ 发现了
保存较好的 Acrograptus 标本, 其始端发育为典型的 isograptid 型(A. lipoldi). 同时他也指出, Acrograptus 可能还具有另一种始端发育型式—artus 型 (A. nicholsoni), 但是由于当时 A. nicholsoni 的标本为薄 膜状保存, 始端发育型式可清晰辨认的可能性不大. 同样, Skwarko ${ }^{[39]}$ 采自澳大利亚的标本 Didymograptus aff. gracilis 也存在类似问题, 始端部分的详细情况不 甚明了. Cooper 和 Fortey ${ }^{[7]}$ 在报道来自斯皮斯卑尔根 的 Acrograptus 标本时, 没有对始端发育进行详细描 述, 对于 Acrograptus 是否存在两种始端发育型式没 有给出明确的说明. Williams 和 Stevens ${ }^{[8]}$ 也仅是描述 了产自加拿大纽芬兰 A. gracilis 的标本, 并未对其始 端发育做详细讨论. 1994 年, Maletz ${ }^{[6]}$ 在对下垂类对 笔石的始端发育研究中指出, Acrograptus 的始端发 育型式可能只有一种, 即 isograptid 型, 且 th $1^{1}$ 在胎管 较高位置生出, 但是未给出确切的证据来支持这一 观点. 由此可见, Acrograptus 的始端发育型式始终未 
能确定, 使得该属在使用上颇为混乱.

为了对 Acrograptus 的始端发育有进一步的认识, 本文对产自湖南益阳南坝剖面的 128 枚 Acrograptus 标本进行了系统研究. 这些标本中包含 3 个种: $A$. affinis (Nicholson), A. gracilis (Törnquist) 以及 $A$. nicholsoni (Lapworth), 它们是最早被归入 Acrograptus 的种类. 南坝的 A. affinis 标本与正模 ${ }^{[1]}$ 基本相似, 始端发育型式为 isograptid 型, th $1^{1}$ 从胎管 较高位置生出, 大致相当于亚胎管始部的位置(图 4(a) (d)). 与挪威的合模 ${ }^{[7]}$ 在始端形态上基本一致, 但后者始端构造无法清晰辨认. 南坝的 A. gracilis 标 本与正模 ${ }^{[40]}$ 特征相似, 其始端可见等称笔石弧 (isograptid arch), th $1^{1}$ 从相当于亚胎管始部的位置生 出, 为典型的 isograptid 型(图 4(e) (h)). 南坝的 $A$. nicholsoni 标本始端保存完好, th $1^{1}$ 自胎管较高位置生 出, 可见两个横管, 始端发育型式也为 isograptid 型 (图 4(i) (1)). Bouček ${ }^{[3]}$ 指出 A. nicholsoni 的始端发育型 式为 artus 型, 但由于标本呈薄膜状保存, 这一观点 曾遭到质疑. 肖承协和陈洪冶 ${ }^{[20]}$ 对江西玉山古城的 该种标本进行了描述, 指出其 th $1^{1}$ 自胎管上部生出, 始部具有一个横管. 如果上述观察无误, 不排除 $A$. nicholsoni 具有两种始端发育型式的可能性.

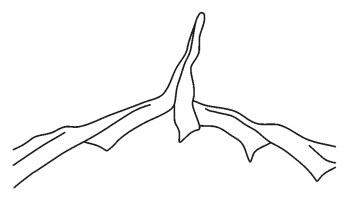

(a)

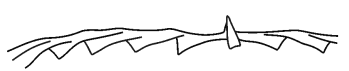

(e)

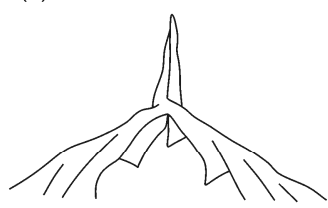

(i)

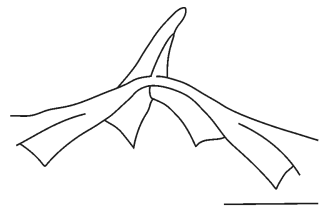

(b)

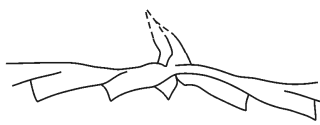

(f)

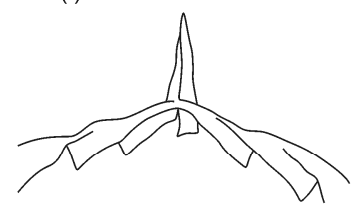

(j)

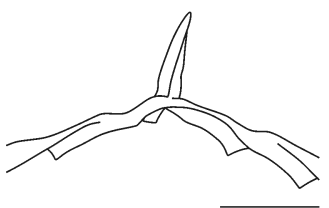

(c)

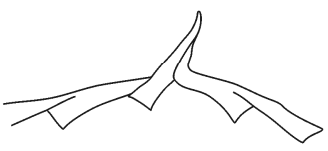

(g)

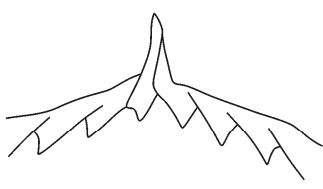

(k)

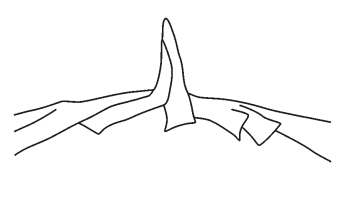

(d)

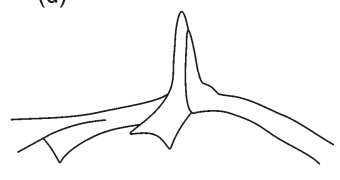

(h)

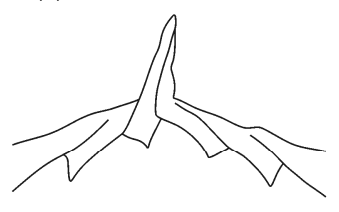

(l)

图 4 尖顶笔石属(Acrograptus)的始端发育图解

(a) (d) Acrograptus affinis (标本号: YYN20.1 9a; YYN20.1 32a; YYN21.2 20b; YYN21.5 31); (e) (h) Acrograptus gracilis (标本号: YYN20.1 2b; YYN21.1 3; YYN21.2 6; YYN21.2 12a;); (i) (1) A. nicholsoni (标本号: YYN20 6; YYN20.1 8; YYN22 4; YYN22 41). 图中比 例尺均为 $1 \mathrm{~mm}$ 
有时会同时具亚胞管褶, 胞管口部内卷, 原胞管和亚 胞管口部还会生出刺. 而弯笔石亚科中的属种胞管 形态简单, 以纤细为主要特征, 简单直管状, 原胞管 部分较长, 更加接近均分笔石科的胞管特征. (2) 在 始端发育型式方面, 中国笔石科包含有两种始端发 育型式: artus 型和 isograptid 型; 均分笔石科始端发 育型式则以 isograptid 型为主, artus 型很少, 含 artus 型的属种多见于奥陶纪中、晚期地层中. 弯笔石亚科 始端发育型式仅有 isograptid 型, 且主要分布于奥陶 纪早、中期地层中, 与均分笔石科特征较为相符. 鉴 于上述原因，本文将弯笔石亚科归入均分笔石科, Acrograptus 也应隶属于均分笔石科.

正笔石目 Order Graptoloidea Lapworth (Hopkinson et Lapworth), 1875

均分笔石亚目 Suborder Dichograptina Lapworth, 1873

均分笔石科 Family Dichograptidae Lapworth, 1873

弯笔石亚科 Subfamily Sigmagraptinae Cooper et Fortey, 1982

尖顶笔石属 Genus Acrograptus Tzaj, 1969

模式种: Didymograptus affinis Nicholson, 1869, p. 240, pl. 11, fig. 20 .

鉴定特征：根据对始端发育型式的最新观察, 本 文将 Acrograptus 的定义厘定如下：笔石体两枝近水 平至下斜伸展, 胎管长且纤细. Th $1^{1}$ 从亚胎管始部生 出, th $1^{2}$ 为双芽胞管, 始端发育型式为 isograptid 型. $\mathrm{Th} 1^{1}$ 和 th $1^{2}$ 在不同水平位置弯离胎管, 使得始端部分 不对称. $\mathrm{Th} 1^{2}$ 与 th $2^{1}$ 的原胞管部分极为纤细, 构成两 个细弱的横管.

讨论：厘定后的 Acrograptus 包括 6 个种, 即 $A$. affinis (Nicholson), A. gracilis (Törnquist), $A$. nicholsoni (Lapworth), A. filiformis (Tullberg), A. pusillus (Tullberg) 以及 A. saukros (Ni). 此外, 对于被 转移至 Acrograptus 中的两个种 Didymograptus kurcki Törnquist 和 Didymograptus ellesae Ruedemann, 笔者 分别选取张元动等 ${ }^{[42]}$ 采自贵州遵义下、中奥陶统湄潭 组的 D. kurcki 标本以及李积金等 ${ }^{[9]}$ 采自江西崇义的 D. ellesae 标本做了详细镜下观察. 在反面保存的标 本中, 可清晰判别二者始端发育型式均为 artus 型, th $1^{1}$ 生出位置较高. 本文认为这两个种的始端发育特
征与 Acrograptus 的定义不符, 因此仍将其保留于 Didymograptus 中.

尼氏尖顶笔石 Acrograptus nicholsoni (Lapworth, 1875)

(图 5(c); 图 $6(\mathrm{~b}),(\mathrm{k})$ )

1875 Didymograptus nicholsoni Lapworth, p. 644, pl. 33, figs. $5 \mathrm{a} \sim \mathrm{d}$.

1973 Acrograptus nicholsoni, Bouček, p. 67, pl. 12, figs. 1 5; text figs. $21 \mathrm{a} \sim \mathrm{f}$.

2002 Didymograptus nicholsoni, 穆恩之等, 第 267 页, 图版 80, 图 9; 图版 81, 图 17 .

讨论：该种由 Lapworth ${ }^{[44]}$ 建立并描述，以笔石 枝近水平伸展、分散角较大 $\left(180^{\circ}\right)$ 为特征. 1901 年, Elles 和 Wood ${ }^{[2]}$ 指出, 该种不仅包括分散角大、近平 伸的笔石个体, 而且还应包括分散角相对较小的个 体(分散角约 $110^{\circ} \sim 130^{\circ}$ ). Monsen ${ }^{[45]}$ 则认为, 这些分 散角较小的个体与该种最初的定义有一定的差别, 应当将其归入新建变种 Didymograptus nicholsoni var. apartus 中. 1973 年, Bouček ${ }^{[3]}$ 修订了该种的定义, 认 为其始端发育型式符合 Acrograptus 的特征, 因此将 其转移至 Acrograptus 中. 同时, 他还将 Monsen ${ }^{[45]}$ 定 义的变种 Didymograptus nicholsoni var. apartus 归入 A. nicholsoni 中. 随后的研究中, 由于 Acrograptus 的 定义尚存争议, 因此仍可见将该种归为广义对笔石 的报道 ${ }^{[21,22]}$.

相近尖顶笔石 Acrograptus affinis (Nicholson, 1869) (图 5(a); 图 $6(\mathrm{a}),(\mathrm{g}) \sim(\mathrm{j})$ )

1869 Didymograptus affinis Nicholson, p. 240, pl. 11, fig. 20. 1937 Didymograptus cf. affinis, Monsen, p. 121, Taf. 2, fig. 43.

1969 Acrograptus affinis, Tzaj, p. 142 143. fig. 1e.

2000 Acrograptus adamantinus (T. S. Hall), 李积金等, 第 65 页, 图版 16, 图 14.

讨论：该种由 Nicholson ${ }^{[46]}$ 建立，并归入对笔石 属中. 1969 年, Tzaj 以该种作为模式种建立了新属 Acrograptus. Monsen ${ }^{[45]}$ 所报道的 Didymograptus cf. affinis, 除了笔石枝始部宽度略小之外, 其他特征均 与该种定义相符, 本文认为应将其归入 A. affinis. 与 Acrograptus 中的其他种类一样，该种也具有特殊的 始端发育型式. 不同的是, 与 A. gracilis 相比, 该种 始部胞管下斜伸展 ${ }^{[7]}$, 枝宽较大, 分散角较小. 该种 与 A. nicholsoni 的主要区别在于, 后者的笔石枝宽度 和胞管密度较大. 2000 年, 李积金等 ${ }^{[9]}$ 在对江西崇义 

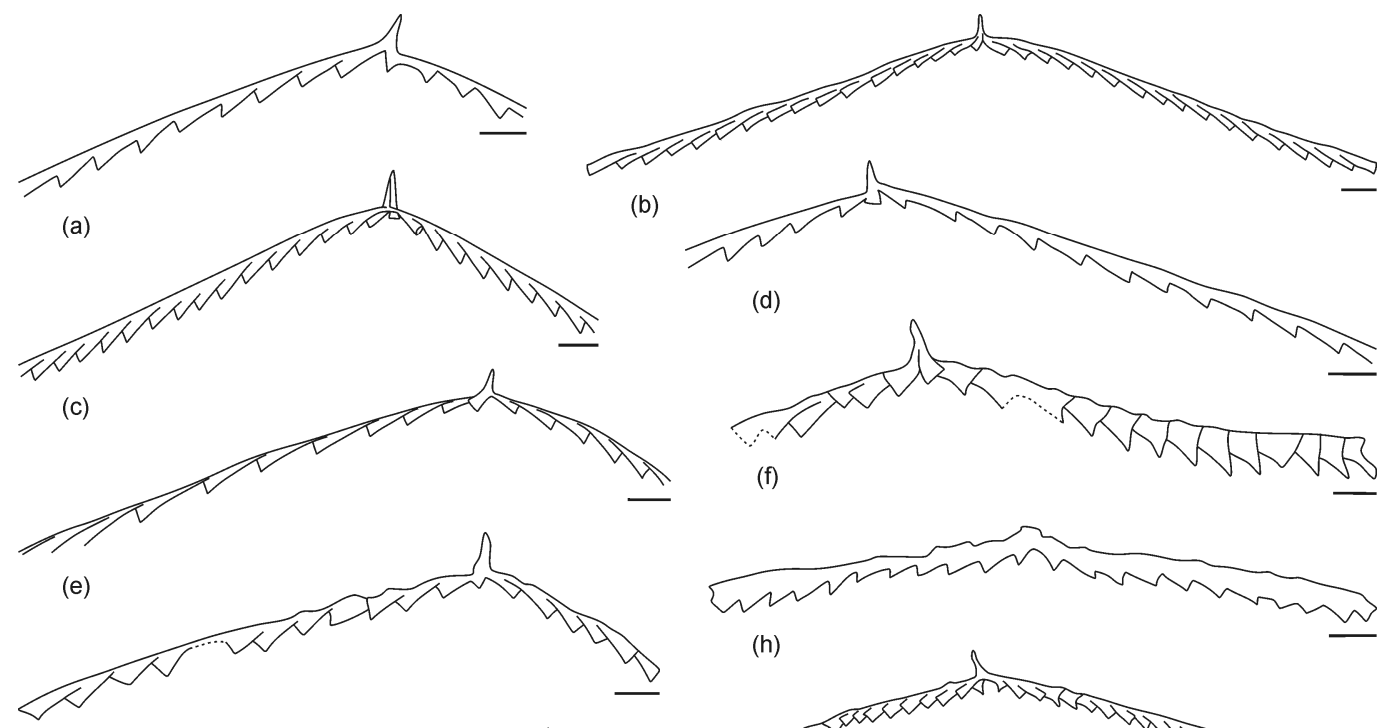

(h)

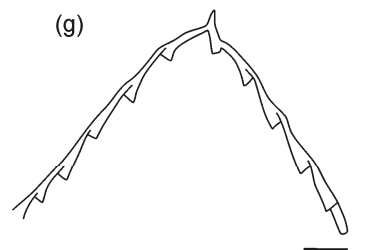

(j)

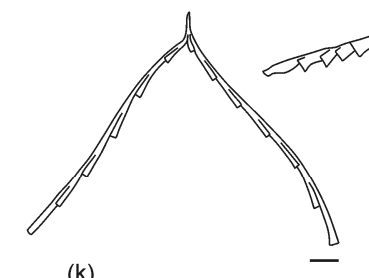

$(\mathrm{k})$ (i)

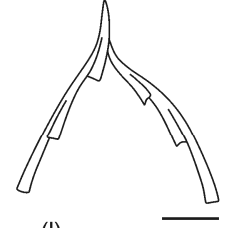

(I)

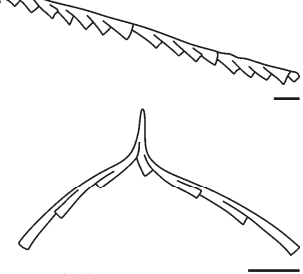

(m)

图 5 厘定后的尖顶笔石属(Acrograptus)各种

(a) Acorgraptus affinis (Törnquist), 湖南益阳南坝, YYN20.1 9a. (b), (g) (h) Acrograptus pusillus (Tullberg). (b) 文献[43], Taf. 2, fig. 12, Kiviks-Esperöd, Scania, Sweden, LO348t; (g) 文献[22], 图版 27, 图 9, 贵州贵阳, F4 124; (h) 文献[20], 图版 20, 图 5, 江西玉山古城, Yc2 34. (c) Acrograptus nicholsoni (Lapworth), 湖南益阳南坝, YYN 20 6. (d) (e) Acrograptus gracilis (Törnquist), 湖南益阳南坝. (d) YYN21.2 9b; (e) YYN21.2 6. (f), (i) Acrograptus saukros (Ni), 文献[22], 图版 28, 图 7, 贵州思南英武溪, AAE610a; 图 8, 四川綦江观音桥, AAE283. (j) (m).Acrograptus filiformis (Tullberg). (j) 文献[22], 图版 27, 图 10, 贵州三都大塘, ACC18; (k) (m) 文献[43], Taf. 2, fig. 10, 8, 9, Kiviks-Esperöd, Scania, Sweden, LO352t, LO350t, LO351t. 图中比例尺均为 $1 \mathrm{~mm}$

早奥陶世的笔石动物群进行研究时, 将 Didymograptus adamantinus T. S. Hall 转移至 Acrograptus 中. 此前, 对于 A. adamantinus 始端发育特征的详细描述 较少, 仅可知该种胎管较短小, th $1^{1}$ 自胎管顶部生出. 笔者对李积金等 ${ }^{[9]}$ 采集的 A. adamantinus 标本进行了 观察, 由于标本正面保存, 始端发育型式仍无法辨认, 仅可见最初两个胞管在不同水平位置生出. 将 $A$. adamantinus 与 A. affinis 各特征对比后发现, 前者除 了始端发育型式不明之外, 其他特征均与 A. affinis 相似. 在获得新的材料明确其始端发育型式之前, 本 文暂将其作为 A. affinis 的次异名.

\section{纤细尖顶笔石 Acrograptus gracilis (Törnquist, 1890)}

(图 5(d) (e); 图 6 (c) (f))

1890 Didymograptus gracilis Törnquist, p. 17, pl. 1, figs. 9 12.

1982 Acrograptus gracilis, Cooper and Fortey, p.272, figs.
$66 \mathrm{c} \sim \mathrm{g}$. 2000 Acrograptus gracilis，李积金等，第66页，图版 17，图 4.

? 2000 Acrograptus hemisolatus Li et al., 李积金等, 第 67 页, 图版 17, 图 1-3.

讨论：Törnquist ${ }^{[40]}$ 指出, 该种最主要特征是前两 个胞管水平伸展, 其次是具有纤细的笔石枝. 虽然该 种长期以来被归入广义的对笔石属中 ${ }^{[2,22,45]}$, 但是其 特殊的始端构造以及纤细的笔石枝与广义对笔石属 中的其他种类明显不同. 值得注意的是，该种双芽胞 管的生长方向既有左旋模式(图 4(e) (f)), 也有右旋 模式(图 4(g) (h)), 这在均分笔石类始端发育中并不 常见. 通过对挪威标本的详细研究, Cooper 和 Fortey ${ }^{[7]}$ 将该种转移至 Acrograptus 之中. 根据采自江西崇义 的笔石标本，李积金等 ${ }^{[9]}$ 建立了新种 Acrograptus hemisolatus. 笔者观察了其正模及副模标本，笔石 

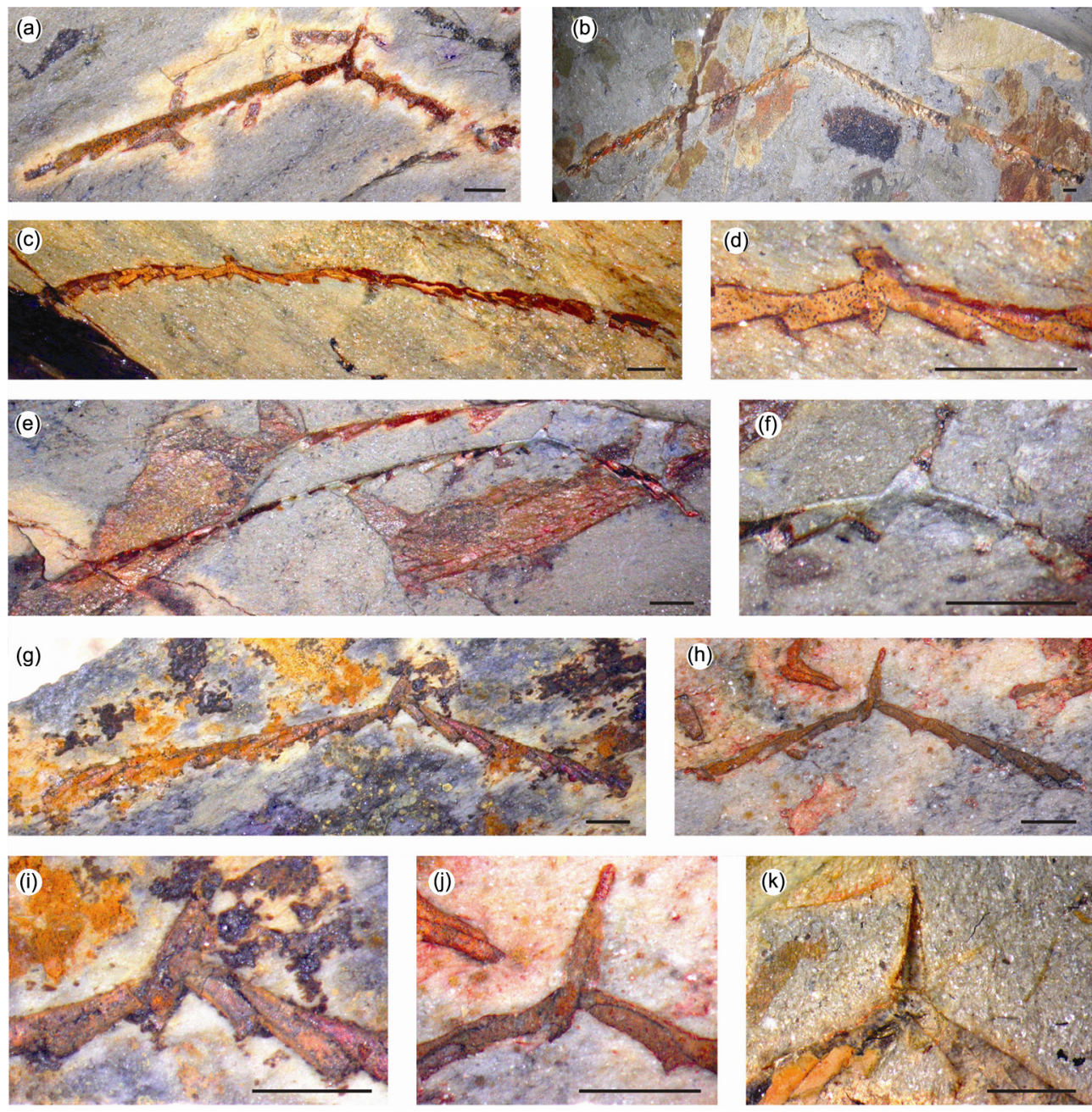

图 6 湖南益阳南坝剖面中的尖顶笔石属(Acrograptus)

(a), (g) (j) Acorgraptus affinis (Törnquist), (a) YYN20.1 9a; (g), (i) YYN20.1 32a; (h), (j). YYN21.2 20b. (b), (k). Acrograptus nicholsoni (Lapworth), YYN20 6. (c) (f). Acrograptus gracilis (Törnquist), (c) (d). YYN21.1 3; (e) (f). YYN21.2 6. 图中比例尺均为 $1 \mathrm{~mm}$

体呈薄膜状保存，始端部分未保存或保存不好，特 征难以辨认；笔石枝及胞管特征却清晰可辨，与 $A$. gracilis 的特征较为相似. 虽然二者产出层位有所不 同(A. hemisolatus 产出层位较 A. gracilis 高很多, 相当 于上奥陶统的下部), 但不排除 A. hemisolatus 是 A. gracilis 的次异名. 若进一步研究证实 A. hemisolatus 的始端发育型式为 isograptid 型, 则可将此类标本归入 A. gracilis 中. 本文暂将 A. hemisolatus 作为 A. gracilis 的次异名.

细线尖顶笔石 Acrograptus filiformis (Tullberg, 1880) (图 5(j) (m))

1880 Didymograptus filiformis Tullberg, S. 42, 43, Taf. 2, figs. $8 \sim 11$.

?1986 Acrograptus cf. filiformis, Rushton et al., p. 47, 48, figs. $3 \mathrm{~g}, \mathrm{~h}$.

讨论：该种在形态上以笔石枝纤细、两枝下斜成 直角为主要特征. 以往关于始端的描述只提到 th $1^{1}$ 从 胎管近顶部生出, 沿胎管壁一侧向下生长, 在近胎管 口部处向外弯转, th $1^{2}$ 则自 th $1^{1}$ 的转折处生出, 而对 于始端发育型式则未做讨论 ${ }^{[20 ~ 22,45,47 \sim 49]}$. 笔者对陈旭 等 ${ }^{[50]}$ 采自浙江常山黄泥塘以及 Zhang 和 Chen ${ }^{[23]}$ 采自 贵州桐梓红花园的标本进行了镜下观察。在反面保 存的标本中, 可以看到 th $1^{1}$ 从胎管较高位置生出, 双 芽胞管为 $\mathrm{th} 1^{2}$, 左手生出, 左旋生长, 始端发育为 
isograptid 型.

细弱尖顶笔石 Acrograptus pusillus (Tullberg, 1880)

(图 5(b), (g) (h))

1880 Didymograptus pusillus Tullberg, S. 42, Taf. 2, figs. 12 14.

1990 Acrograptus pusillus, 肖承协, 陈洪冶, 第 134 页, 图 版 20, 图 5,14, 15.

讨论：该种长期以来被置于 Didymograptus 中, 其始端发育特征不明 ${ }^{[18,21,22,45,51]}$. Monsen ${ }^{[45]}$ 采自挪威 的标本多为正面保存(Tafel 2, Figure 21, 50), 始端发 育型式无法辨认, 仅可见 th $1^{1}$ 从胎管较高位置生出, 始端最初两个胞管从不同水平位置生出. Toro ${ }^{[52]}$ 在阿 根廷也发现了与该种相似的标本 (Acrograptus cf. pusillus), 从其给出的图版(pl. 3,11 12)不难看出, 阿 根廷的标本虽始端发育为 isograptid 型, 但是 th $1^{1}$ 从 胎管中部生出, 较典型的 A. pusillus 低, 且笔石枝背 缘褶曲显著, 不宜归入该种. 穆恩之等 ${ }^{[22]}$ 指出, 该种 th $1^{1}$ 从胎管中部生出, th $1^{2}$ 从 th $1^{1}$ 转弯处生出, 但始端 发育型式在图版中不易确认，肖承协和陈洪冶 ${ }^{[20]}$ 采 自江西玉山的标本仅能看到笔石体轮廓, 始端特征 较难辨认. 笔者详细观察了 Zhang 和 $\mathrm{Chen}^{[23]}$ 采自贵 州桐梓红花园的标本, th $1^{1}$ 从胎管较高位置生出, th $1^{2}$ 为双芽胞管, 右手生出, 右旋生长, 始端发育为 isograptid 型, 横管纤细, 其始端发育特征及胞管、笔 石枝等特征均与 Acrograptus 的特征一致.

华美尖顶笔石 Acrograptus saukros (Ni, 1979) (图 5(f), (i))

1979 Didymograptus saukros Ni, p. 81, pl. 28, figs. 7 12. 2003 Acrograptus saukros, 陈旭等, 第 483 页, 插图 2.

讨论：倪寓南 ${ }^{[22]}$ 根据西南地区的笔石标本建立 该种, 并将其归入 Didymograptus 之中. 她对该种的 始端发育特征作了较为详细的描述: th $1^{1}$ 从胎管顶部 生出, 在胎管中下部弯曲向外, th $1^{2}$ 从 th $1^{1}$ 弯曲处生出, 并斜横过胎管, th $2^{1}$ 和 th $1^{2}$ 从同一高度生出, 始端发育 型式为 isograptid 型. 该种不仅在西南地区出现 ${ }^{[22,53]}$, 在浙江一带也有报道 ${ }^{[50]}$. 笔者观察了采自浙江常山 黄泥塘的该种标本，正面保存的标本无法辨认始端 发育型式, 但是可以看出 th $1^{1}$ 生出位置较高; 反面保 存的标本始端发育型式均为 isograptid 型, 个别可见 等称笔石弧(isograptid arch). 从其初始定义及所发现 的标本特征来看, 该种较符合本文对 Acrograptus 的
定义，应归入其中

\section{Acrogratptus 的扩散型式}

Acrograptus 一属在华南分布范围较广, 从扬子 台地到江南斜坡带乃至东南盆地均有报道. 如图 1 虚 线圈中区域所示，该属集中分布于代表浅水相的上 扬子台地以及深水相的江南斜坡带中东部, 主要产 自泥质或富含泥质的沉积带内, 其余区域也有零星 分布，但丰度及分异度均较低。

图 7 展示了 6 种 Acrograptus 在扬子区和江南区 的纵向分布情况. 由于受标本保存状况等因素的影 响, 东南区笔石生物地层研究程度较低, 本文暂不对 东南区的资料进行详细讨论. 从图中可以看出, 最早 出现的两个种 A. nicholsoni 和 A. pusillus 首现于弗洛 早期的 Tetragraptus approximatus 带, 这一时期 Acrograptus 仅限于江南区, 且分异度较低. 弗洛中 期 (Pendeograptus fruticosus 带 Didymograptellus bifidus 带), Acrograptus 迅速繁荣，在江南区新增 4 个 种, 即 A. affinis, A. gracilis, A. filiformis 以及 A. saukros, 种数达到 6 个; 在扬子区，这 6 个种也基本同 期出现，除 A. nicholsoni 和 A. pusillus 之外，其余 4 种 的首现层位在扬子区和江南区一致. 此时, 无论扬子 区或江南区 Acrograptus 的丰度和分异度均处于高潮. 弗洛晚期(Corymbograptus deflexus 带 Azygograptus suecicus 带), 扬子区和江南区 Acrograptus 的种数均 呈下降趋势，扬子区的下降幅度相对较大. 至大坪初 期, Acrograptus 在扬子区 Azygograptus suecicus 带顶 部仅存 2 个种，在江南区同期地层中也减至 2 个. 此 后，除了延限较长的 A. gracilis 一直到达瑞威尔晚期 的Pterograptus elegans 带才灭绝, 其余各种延限均未 超过大坪阶顶界. 在南坝剖面, Acrograptus 最早出现 于弗洛期 Pendeograptus fruticosus 带, 但是丰度和分 异度均较低. 至 Didymograptellus bifidus 带, 该属迅 速繁盛, 共发现 3 个种, 其延限贯穿整个 Didymograptellus bifidus 带, 其中一种上延至 Corymbograptus deflexus 带.

从 Acrograptus 在华南的分布规律来看，该属最 早出现于水体较深的斜坡相区，进入弗洛中期，属内 各种不仅在斜坡地区空前繁盛，而且在较浅水的台 地相区广泛分布.

对于营漂浮生活的 Acrograptus 来说, 深水斜坡 


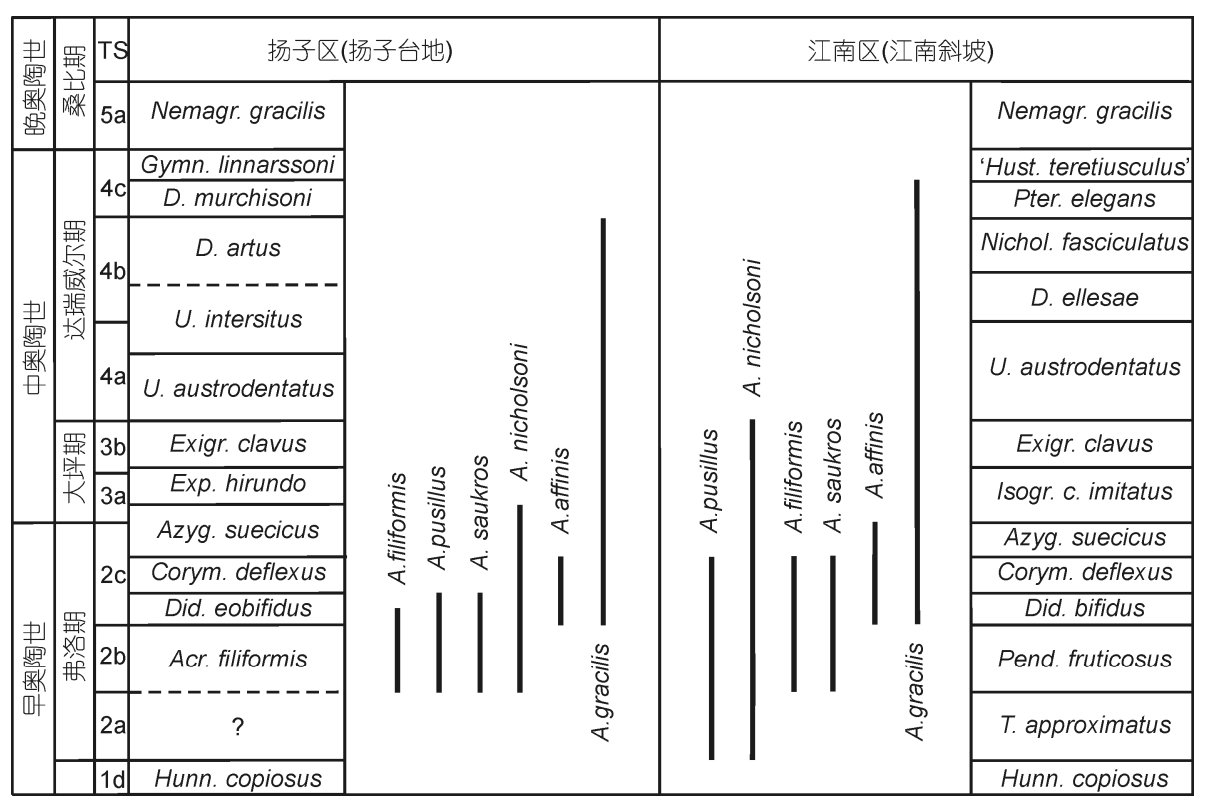

图 7 华南早、中奥陶世尖顶笔石属(Acrograptus)的地层延限

扬子区材料来自文献[21 23,48,53 58]1,2); 江南区材料来自文献[9,17 21,49,59 63]. 笔石带序列修改自文献[25]

环境对其辐射演化尤为重要. 深水斜坡处于上升流 活跃地带, 初级生产力较高, 富营养的水团可为笔石 幼体的生长提供充足的食物来源 ${ }^{[64 ~ 68]}$. 此外, Acrograptus 可能是由一类反称笔石 Adelograptus antiquus (T. S. Hall)演化而来 ${ }^{[69]}$, 因反称笔石类一般 生活于较深水环境, 故而 Acrograptus 的发源地很可 能就是水体较深的斜坡地区.

在适应了较深水的斜坡环境后, Acrograptus 开 始通过扩散方式拓展生存空间. 其扩散型式主要表 现为横向的生态分异和生态带迁移 ${ }^{[68]}$. Acrograptus 在横向上的生态分异主要是指从弗洛中期(相当于 Pendeograptus fruticosus 带)开始, 该属跨越相区的界 线, 在浅水台地大量繁盛. 此时, 早期出现于斜坡地 区的种类(A. nicholsoni, A. pusillus), 一方面朝更利于 漂浮生存的方向演化, 产生适应在较浅水及表层水体 中生存的新种类; 另一方面, 随着海平面上升, 台地 相区水深加大, 这些较早出现的种类其生境由斜坡向 台地迁移, 在适应台地环境后开始演化出新的种类.

从宏演化的角度来看, Acrograptus 的起源、繁盛 直至衰亡恰好处于奥陶纪笔石动物辐射演化的关键 时期(早、中奥陶世). 其中, 早奥陶世弗洛期是反称
笔石动物群向均分笔石动物群演化的重要阶段 ${ }^{[58]}$. 作为均分笔石动物群中出现较早的类群, Acrograptus 起源于早奥陶世晚期(弗洛期)的深水斜坡地区，可能 是演化新质的携带者之一, 为均分笔石动物群的辐 射演化提供了新的途径. 通过与华南笔石动物群宏 演化过程 ${ }^{[70]}$ 的对比发现, Acrograptus 在扬子区和江 南区的多样性曲线与华南相应地层区的笔石种级分 异度曲线基本一致, 多样性峰值分别位于弗洛中期 (Acrograptus filiformis 带 Didymograptellus eobifidus 带)和弗洛晚期(Corymbograptus deflexus 带); 而在弗 洛期之后, 伴随着新类群(舌笔石类及双笔石类)的出 现, 均分笔石动物群开始呈衰退趋势, 此时 Acrograptus 的分异度也逐渐下降, 并在中奥陶世末 灭绝.

综上所述, Acrograptus 在弗洛期 Pendeograptus fruticosus 带初经历了一次明显的扩散事件, 属内各 种由斜坡向台地大范围迁移. 究竟是什么因素触发 了此次扩散事件? 一般认为, 笔石的扩散主要受控 于内、外两方面因素, 内因主要是笔石动物群自身的 演替; 在外因方面, 则存有诸多假说, 如全球性板块 构造运动、火山作用、海平面升降等 ${ }^{[68,71 ~ 75]}$. 然而,

2) 高道德. 贵州的奥陶系. 惠水: 贵州地质局地层古生物工作队地层组, 1976. 104 
这诸多因素中, 大多在地质记录上难以找到直接证据. 通过对华南Acrograptus 的研究发现, 其横向上的生态 分异主要受控于该属自身的演化规律及海平面变化, 同时, 海平面变化更直接影响着该属生境的侧向迁 移 ${ }^{[68]}$. 值得关注的是, $\mathrm{Su}^{[76]}$ 通过对华南板块沉积学及 层序地层学的相关研究, 识别出奥陶系一系列海进-海
退事件. 其中, 在弗洛中期(大致相当于 P. fruticosus 带)发生了一次大规模海侵事件, 海平面持续升高, 直 至弗洛期末, 海平面才趋于平稳或略有下降(见文献 [76]的插图 3), 这一海侵事件与 Acrograptus 在华南的 扩散恰好对应. 因此, 作者推测, Acrograptus 发生于 弗洛期的扩散事件可能与海侵事件密切相关.

致谢在文稿准备和撰写过程中, 中国科学院南京地质古生物研究所张元动研究员提出了宝贵意见, 并提供相关化 石标本供笔者观察. 标本观察过程中得到了中国科学院南京地质古生物研究所标本馆王志勤高级工程师的 大力支持. 瑞典隆德大学 Per Ahlberg 教授以及美国科罗拉多州立大学 Jörg Maletz 博士协助查验了现存于隆 德大学的 Tullberg (1880)所报道的笔石标本, 并提供了 Acrograptus 相关线条图、照片及图件说明. 评审人提 出建设性的修改意见，作者在此一并谨致诚挚的谢意.

\section{参考文献}

1 Tzaj D T. A new Ordovician genus Acrograptus. Paleont Zh, 1969, 1: 142-143

2 Elles G L, Wood E M R. Monograph of British graptolites, Part 1. Palaeontogr Soc (Monogr), 1901. 1-54

3 Bouček B. Lower Ordovician Graptolites of Bohemia. Prague: Academia Publishing House of the Czechoslovak Akademy of Sciences, 1973. 1-185

4 Bulman O M B. On the graptolites prepared by Holm 7. The graptolite fauna of the Lower Orthoceras Limestone of Hälludden, Öland, and its bearing on the evolution of the Lower Ordovician graptolites. Arkiv för Zoologie, 1936, 28A: 1-107

5 Skevington D. Graptolites from the Ontikan Limestones (Ordovician) of Öland, Sweden. II. Graptoloidea and Graptovermida. Bull Geol Inst Univ Uppsala, 1965, 43: 1-74

6 Maletz J. Pendent didymograptids (Graptoloidea, Dichograptacea). In: Chen X, Erdtmann B D, Ni Y N, eds. Graptolite Research Today. Nanjing: Nanjing University Press, 1994. 27-43

7 Cooper R A, Fortey R A. The Ordovician graptolites of Spitsbergen. Bull Br Mus Nat Hist (Geol), 1982, 36: 157-302

8 Williams S H, Stevens R K. Early Ordovician (Arenig) graptolites of the Cow Head Group, western Newfoundland, Canada. Palaeontogr Canadiana, 1988, 5: 1-167

9 李积金, 肖承协, 陈洪冶. 江西崇义早奥陶世宁国期典型太平洋笔石动物群. 中国古生物志, 2000, 189: 1-188

10 赖才根. 中国的奥陶系. 北京: 地质出版社, 1982. 1-297

11 Feng H Z, Erdtmann B D. Early Tremadoc graptolite sequence in the Wuning area, South China and its international correlation. Acta Univ Carolinae (Geol), 1999, 43: 21-24

12 张允白, 周志毅, 张俊明. 扬子陆块早奥陶世末期-中奥陶世 Darriwilian 初期沉积分异. 地层学杂志, 2002, 26: 302-313

13 冯洪真, 李明, 张元动, 等. 华南上特马道克阶的笔石带序列及其全球对比. 中国科学 D 辑: 地球科学, 2009, 39: 556-568

14 Feng H Z, Erdtmann B D, Li M, et al. New data on upper Tremdocian to lower Floian graptolite succession in South China. In: Li J, Fan J X, Percival I, eds. Proceedings of the 10th ISOS, 3rd ISSS and IGCP 503. Acta Palaeontol Sin, 2007, 46(Suppl): 120-127

15 李丽霞, 冯洪真, 李明, 等. 湖南益阳下奥陶统弗洛阶的笔石分带. 地层学杂志, 2009, 33: 123-137

16 李丽霞, 冯洪真, 王文卉. 湖南益阳早奥陶世弗洛期的笔石. 古生物学报, 2010, 49: 174-195

17 陈旭，韩乃仁. 江西玉山早奥陶世笔石地层. 地质论评, 1964, 22: 81-90

18 陈旭, 杨达铨, 韩乃仁, 等. 江西玉山下奥陶统宁国组底部工字笔石带的笔石. 古生物学报, 1983, 22: 324-330

19 陈旭, 杨达铨. 江西玉山早奥陶世笔石动物群的分带及分异. 地层学杂志, 1988, 12: 112-124

20 肖承协, 陈洪冶. 玉山古城一带早中奥陶世笔石动物群. 江西地质, 1990, 4: 83-243

21 穆恩之, 李积金, 葛梅钰, 等. 中国笔石. 北京: 科学出版社, 2002. 1-1042

22 穆恩之, 葛梅钰, 陈旭, 等. 西南地区下奥陶统的笔石. 中国古生物志, 1979, 156: 1-192

23 Zhang Y D, Chen X. The Early-Middle Ordovician graptolite sequence of the Upper Yangtze region, South China. In: Albanesi G L, Beresi M S, Peralta S H, eds. Ordovician from the Andes. INSUGEO, Serie Correlación Geológica, 2003, 17: 173-180

24 Zhan R B, Jin J S. Ordovician-Early Silurian (Llandovery) stratigraphy and palaeontology of the Upper Yangtze Platform, South China. 
Beijing: Science Press, 2007. 1-169

25 Zhang Y D, Chen X, Goldman D, et al. Diversity and paleobiogeographic distribution patterns of Early and Middle Ordovician graptolites in distinct depositional environments of South China. Sci China Earth Sci, 2010, 53: 1811-1827

26 Elles G L. The graptolite faunas of the British Isles: A study in evolution. Proc Geol Assoc, 1922, 33: 168-220

27 Holm G. Gotlands Grptolites. Bih K svenska Vetensk Akad Handl, 1890, 16: 1-34

28 Holm G. On Didymograptus, Tetragraptus and Phyllograptus. Geol Mag, 1895, 32: 433-492

29 Wiman C. Üeber Diplograptidae Lapworth. Bull Geol Inst Univ Uppsala. 1893, 1: 97-103

30 Wiman C. Über die Graptolithen. Bull Geol Inst Univ Uppsala. 1895, 2: 239-316

31 Bulman O M B. Notes on the evolution and morphology of certain Graptoloidea. Arkiv för Zoologie, 1932, 24A: 1-37

32 Bulman O M B. Graptolithina with sections on Enteropneusta and Pterobranchia. In: Moore R C, ed. Treatise on invertebrate palaeontology, Part V. Boulder and Lawrence: Geological Society of America and University of Kansas Press, 1955. 1-101

33 Bulman O M B. Graptolithina with sections on Enteropneusta and Pterobranchia. In: Teichert C, ed. Treatise on Invertebrate Palaeontology, Part V. 2nd ed. Boulder and Lawrence: Geological Society of America and University of Kansas Press, 1970. 1-163

34 Cooper R A, Fortey R A. Development of the graptoloid rhabdosome. Alcheringa, 1983, 7: 201-221

35 Fortey R A, Cooper R A. A phylogenetic classification of the graptoloids. Palaeontology, 1986, 29: 631-654

36 Fortey R A, Zhang Y D, Mellish C. The relationship of biserial graptolites. Palaeontology, 2005, 48: 1241-1272

37 Carlucci J, Maletz J. Phylogenetic classification and early evolution of the Dichograptacea. GSA Abstracts with Programs, 2007, 39: 72

38 Toro B A, Maletz J. The proximal development in Cymatograptus (Graptoloidea) from Argentina and its relevance for the early evolution of the Dichograptacea. J Paleont, 2008, 82: 974-983

39 Skwarko S K. Some Ordovician graptolites from the Canning Basin, Western Australia, 2: Graptolites from the Goldwyer No. 1 well. Bull Bur Miner Res, 1974, 150: 43-54

40 Törnquist S L. Undersökningar öfver Siljansområdets graptoliter. Lunds Univ Årsskr, 1890, 26: 1-33

41 穆恩之. 浙江常山宁国页岩中的一些新笔石. 古生物学报, 1957, 5: 369-437

42 张元动, 刘晓, 詹仁斌. 贵州遵义高桥奥陶系涺潭组下部的笔石. 古生物学报, 2007, 46: 145-166

43 Tullberg S A. Några Didymograptus-artus i undre graptolitskiffer vid Kiviks-Esperöd. Geol Fören Stockholm Förh, 1880, 5: 39-43

44 Hopkinson J, Lapworth C. Description of the graptolites of the Arenig and Llandeilo rocks of St. David's. Quart Jour Geol Soc Lond, 1875, 31: 631-672

45 Monsen A. Die graptolithenfauna im Unteren Didymograptusschiefer (Phyllograptusschiefer) Norwegens. Norsk geol Tidsskr, 1937, 16: $57-267$

46 Nicholson H A. On some new species of graptolites. Ann Mag nat Hist (Ser 4), 1869, 4: 231-242

47 Ruedemann R. Graptolites of New York, Part I. Graptolites of the lower beds. Mem N Y State Mus, 1904, 7: 457-807

48 李积金, 陈旭. 黔南三都寒武纪及奥陶纪笔石. 古生物学报, 1962, 10: 12-30

49 Toro B A, Brussa, E D. Graptolites. In: Benedetto J L, ed. Ordovician Fossils of Argentina. Cordoba: Universidad Nacional de Cordoba, 2003. 441-505

50 陈旭, 徐红根, 俞国华, 等. 浙江常山黄泥塘 Didymograptus (Corymbograptus) deflexus 带的笔石. 古生物学报, 2003, 42: 481-491

51 杨达铨, 倪寓南, 李积金, 等. 笔石纲. 见: 地质矿产部南京地质矿产研究所, 编. 华东地区古生物图册 (一): 早古生代分册. 北京: 地质出版社, 1983. 353-508

52 Toro B A. La fauna de graptolitos de la Formación Acoite, en el borde occidental de la Cordillera Oriental Argentina. Análisis bioestratigráfico. Ameghiniana, 1997, 34: 393-412

53 王传尚, 汪啸风, 陈孝红, 等. 华南下/中奥陶统界线附近笔石相的分异与全球下/中奥陶统界线生物标志的选择. 现代地质, 2004, 18: 89-95

54 穆恩之. 中国含笔石地层. 北京: 地质出版社, 1959. 1-75

55 张文堂. 中国的奥陶系. 北京: 科学出版社, 1962. 1-161

56 胡荣民. 云南的奥陶系. 昆明: 云南省地质科学研究所, 1976. 1-266

57 安徽省地质局区域地质调查队. 安徽笔石化石. 合肥: 安徽科学技术出版社, 1982. 1-145

58 Zhang Y D, Chen X, Goldman D. Diversification Patterns of Early and Mid Ordovician Graptolites in South China. Geol J, 2007, 42: 315-337

59 刘季辰, 赵亚曾. 浙江西部之地质. 地质汇报, 1927, 9: 51-73

60 高平. 江西玉山、广丰二县地质矿产. 中央地质调查所地质汇报, 1933, 23: 1-20 
61 王小青, 刘祖彝. 湖南长常区地质志. 湖南地质调查所专报乙种. 1936, 1: 6-19

62 刘辉泗. 玉山贵溪间地质. 江西地质调查所地质汇刊, 1941, 6: 1-83

63 湖南省地质与矿产资源局. 湖南省区域地质志. 北京: 地质出版社, 1988. 1-178

64 Berry W B N, Wilde P, Quinby-Hunt M S. The oceanic nonsulfidic oxygen minimum zone: A habitat for the graptolites? Bull Geol Soc Denmark, 1987, 35: 103-114

65 Finney S C, Berry W B N. New perspectives on graptolite distributions and their use as indicators of platform margin dynamics. Geology, 1997, 25: 919-922

66 Cooper R A, Fortey R A, Lindholm K. Latitudinal and depth zonation of Early Ordovician graptolites. Lethaia, 1991, 24: 199-218

67 Cooper R A. Towards a general model for the depth ecology of graptolites. In: Gutiérrez-Marco J C, Rábano I, eds. Proceedings 6th International Graptolite Conference (GSW-IPA) and 1998 Field Meeting. IUGS Subcommission on Silurian Stratigraphy. Temas GeológicoMineros ITGE, 1998, 23: 161-163

68 Cooper R A. Ecostratigraphy, zonation and global correlation of earliest Ordovician planktic graptolites. Lethaia, 1999, 32: 1-16

69 Rushton A W A, Stone P, Smellie J L, et al. An early Arenig age for the Pinbain sequence of the Ballantrae Complex. Scott J Geol, 1986, 22: $41-54$

70 张元动, 陈旭. 奥陶纪笔石动物的多样性演变与环境背景. 中国科学 $\mathrm{D}$ 辑: 地球科学, 2008, 38: 10-21

71 Miller A I, Mao S G. Association of orogenic activity with the Ordovician radiation of marine life. Geology, 1995, 23: 305-308

72 Miller A I. Dissecting global diversity patterns: Examples from the Ordovician Radiation. Annu Rev Ecol Syst, 1997, 28: 85-104

73 Shields G A, Veizer J. Isotopic signatures. In: Webby B D, Paris F, Droser M L, et al, eds. The Great Ordovician Biodiversification Event. New York: Columbia University Press, 2004. 68-71

74 Harper D A T. The Ordovician biodiversification: Setting an agenda for marine life. Paleogeogr Paleoclimatol Paleoecol, 2006, 232: $148-166$

75 张元动, 詹仁斌, 㚞隽轩, 等. 奥陶纪生物大辐射研究的关键科学问题. 中国科学 D 辑: 地球科学, 2009, 39: 129-143

76 Su W B. Ordovician sea-level changes: Evidence from the Yangtze Platform. In: Li J, Fan J X, Percival I, eds. Proceedings of the 10th ISOS, 3rd ISSS and IGCP 503. Acta Palaeontol Sin, 2007, 46 (Suppl): 471-476 